ACCEPTED MANUSCRIPT

\title{
Culture surfaces induce hypoxia-regulated genes in human mesenchymal stromal cells
}

To cite this article before publication: Bo Zhang et al 2019 Biomed. Mater. in press https://doi.org/10.1088/1748-605X/ab0e61

\section{Manuscript version: Accepted Manuscript}

Accepted Manuscript is "the version of the article accepted for publication including all changes made as a result of the peer review process, and which may also include the addition to the article by IOP Publishing of a header, an article ID, a cover sheet and/or an 'Accepted Manuscript' watermark, but excluding any other editing, typesetting or other changes made by IOP Publishing and/or its licensors"

This Accepted Manuscript is @ 2018 IOP Publishing Ltd.

During the embargo period (the 12 month period from the publication of the Version of Record of this article), the Accepted Manuscript is fully protected by copyright and cannot be reused or reposted elsewhere.

As the Version of Record of this article is going to be / has been published on a subscription basis, this Accepted Manuscript is available for reuse under a CC BY-NC-ND 3.0 licence after the 12 month embargo period.

After the embargo period, everyone is permitted to use copy and redistribute this article for non-commercial purposes only, provided that they adhere to all the terms of the licence https://creativecommons.org/licences/by-nc-nd/3.0

Although reasonable endeavours have been taken to obtain all necessary permissions from third parties to include their copyrighted content within this article, their full citation and copyright line may not be present in this Accepted Manuscript version. Before using any content from this article, please refer to the Version of Record on IOPscience once published for full citation and copyright details, as permissions will likely be required. All third party content is fully copyright protected, unless specifically stated otherwise in the figure caption in the Version of Record.

View the article online for updates and enhancements. 


\title{
Culture Surfaces Induce Hypoxia-Regulated Genes in Human Mesenchymal Stromal Cells
}

\author{
Bo Zhang ${ }^{1,2,+}$, Naresh Kasoju ${ }^{1,+, \#}$, Qiongfang $\mathrm{Li}^{3 \dagger}$, Erfan Soliman ${ }^{1}$, Aidong Yang ${ }^{2}$, Zhanfeng
} Cui $^{1,4}$, Jinmin $\mathrm{Ma}^{3,}{ }^{*}$, Hui Wang ${ }^{1,3,4,},{ }^{*}$, Hua $\mathrm{Ye}^{1,4,{ }^{*}}$

\section{${ }^{1}$ Institute of Biomedical Engineering, Department of Engineering Science, University of} Oxford, Oxford, United Kingdom.

${ }^{2}$ Department of Engineering Science, University of Oxford, Oxford, United Kingdom.

\section{${ }^{3}$ BGI-Shenzhen, Shenzhen 518083, China.}

${ }^{4}$ Oxford-Suzhou Centre for Advanced Research (OSCAR), Suzhou, China.

${ }^{*}$ Correspondence and requests for materials should be addressed to J.M. (email: majinmin@genomics.cn), H.W. (email: huiwang789@gmail.com) and H.Y. (email: hua.ye@eng.ox.ac.uk)

'These authors contributed equally.

\# Current affiliation: Biomedical Technology Wing, Sree/Chitra Tirunal Institute for Medical
Sciences and Technology, Thiruvananthapuram 695012, Kerala, India

\section{Abstract}

Culturing human Mesenchymal stromal cells (hMSCs) in vitro in hypoxic conditions resulted in reduced senescence, enhanced pluripotency and altered proliferation rate. It has been known that in vitro hypoxia affects expression of cell surface proteins. However, the impact of culture surfaces on the hypoxia-regulated genes (HRG) have not yet been reported. This study utilized Next-Generation sequencing to analyse the changes in the gene expression levels of HRG for hMSCs cultured on different culture surfaces. The samples, which were cultured on four different synthesized surfaces (treatments) and tissue culture plate (control), resulted in a difference in growth rate. The sequencing results revealed that the transcription of a number of key genes involved in regulating hypoxic functions were significantly altered, including HIF2A, a marker for potency, differentiation, and various cellular functions. Significant alternations in the expression levels of previously reported oxygensensitive surface proteins were detected in this study, some of which closely correlate with the expression levels of HIF2A. Our analysis of the hMSCs transcriptome and HRG mapped out a list of genes encoding surface proteins which may directly regulate or be regulated by HIF2A. The findings from this study showed that culture surfaces have an impact on regulating the expression profile of HRG. Therefore, novel culture surfaces may be designed to selectively activate HIF2A and other HRG and pathways under in vitro normoxia. The understanding of the crosstalk between the regulating genes of hypoxia and culture surfaces may be utilized to strengthen desired hypoxic functions. 


\section{Introduction}

The culturing of human Mesenchymal stromal cells (hMSCs) in hypoxia has shown benefits in reducing senescence, preserving pluripotency, and improving anti-oxidative defence [1-5]. However, contradictory evidence has been reported on the rate of proliferation $[1,3,6-10]$ and the differentiation potential [1, 11-16] of hMSCs cultured in hypoxia. Similarly, the production of reactive oxygen species (ROS) has been the subject of some debate in hypoxic conditions [17-19]. These contrasting results may well have arisen from a wide range of factors, including for example, different levels of hypoxia, cell source, cell pool heterogeneity, donor-to-donor variation, culture conditions and extraction techniques [20-23].

Recent developments in the field of materials science and engineering have facilitated the use and study of different biomaterials to regulate stem cells proliferation and differentiation [24-26]. For instance, Lee et al. demonstrated that bone-marrow-derived hMSCs cultured on biomimetic polyacrylamide based hydrogel substrates were able to differentiate without the use of expensive and unreliable media supplements [27]. Furthermore, a significant number of reports have demonstrated that by fine tuning the biomaterial substrate properties, such as topography, chemistry, stiffness, etc., it is possible to modulate MSCs responses [28-33]. Cukierman et al. reported enhanced cell biological activities and narrowed integrin usage of cells merely by switching to a three-dimensional substrate topography [34]. Furthermore, Guvendiren and Burdick revealed that the spatial and temporal alignment and organization of hMSCs can be reversibly controlled by the topography and substrates of the culture surfaces [35]. Similarly, Phillips et al. demonstrated the induction of osteogenic and adipogenic differentiation in hMSCs by functionalizing the culture surface with amine groups [36]. The modification of surface properties may be inter-dependent in modulating the fate of hMSCs by unconventional mechanisms. Zhang et al. reported a synergistic effect of substrate topography and chemistry on the adhesion and differentiation of canine bone-marrow-derived MSCs [37]. Several other notable investigations have also described the effects of other materials properties on stem cells $[28,32,38,39]$.

To date, only a few culture parameters have been studied to regulate hMSCs behaviour, i.e. oxygen tension, metabolic feed, and cell-surface interaction. hMSCs are plastic adherent by nature, and the cell-surface interaction is primarily dictated by the characteristics of the applied surface in a static culture environment. The cellular effects induced by these three parameters are expected to be interlinked, as shown in Figure 1. Hypoxia has been shown to alter the rate of metabolic uptake and favour the glycolytic pathway for energy production; in addition, survival under hypoxia is strictly 
dependent on glucose availability [40-42]. Glucose has also been found to induce the production of ROS and to regulate the expression of HIF1A, a pivotal transcription factor in the biological response to hypoxia $[43,44]$. Similarly, the impact of culture surfaces on glucose uptake, and vice versa, have been reported $[45,46]$. Hypoxic conditions and the presence of elevated ROS were found to alter surface proteins and the arrangement of the extra-cellular matrix [47-50]. However, the impact of culture surface on regulating hypoxic pathways has not been investigated. Azevedo et al. prepared a type of "bioactive glass" that can induce hypoxic responses based on the dissolution of Cobalt ions [51]. The stabilization effect observed in their study was chemically induced, by a hypoxia mimicking agent, not caused by the alteration of surface interactions. The possibility of culture surfaces regulating the expression of hypoxia-regulated genes (HRG) remains to be elucidated. This may be due to the challenges in capturing a global representation of the induced changes by culture surfaces from traditional cell culture surfaces. With the development of Next-Generation sequencing (NGS) the expression levels of the entire transcriptome can be easily measured, effectively capturing genomewide changes in gene expression $[52,53]$. A number of studies and reviews have addressed the relative advantages of this technique [54-56].

Figure 1: Current knowledge on the interactions between the three key culture parameters [40-50].

This study aims to address the missing knowledge gap on whether culture surfaces can induce HRG, which in turn can be used to emphasize specific hypoxic functions in the future. The commercial hMSCs were cultured on four șurfaces which were prepared in-house. The NGS technique was applied to obtain a global gene expression of each sample [32], from which the HRG were analysed. This study provides novel insights into the novel application of designing culture surfaces to selectively activate hypoxia-regulated functions.

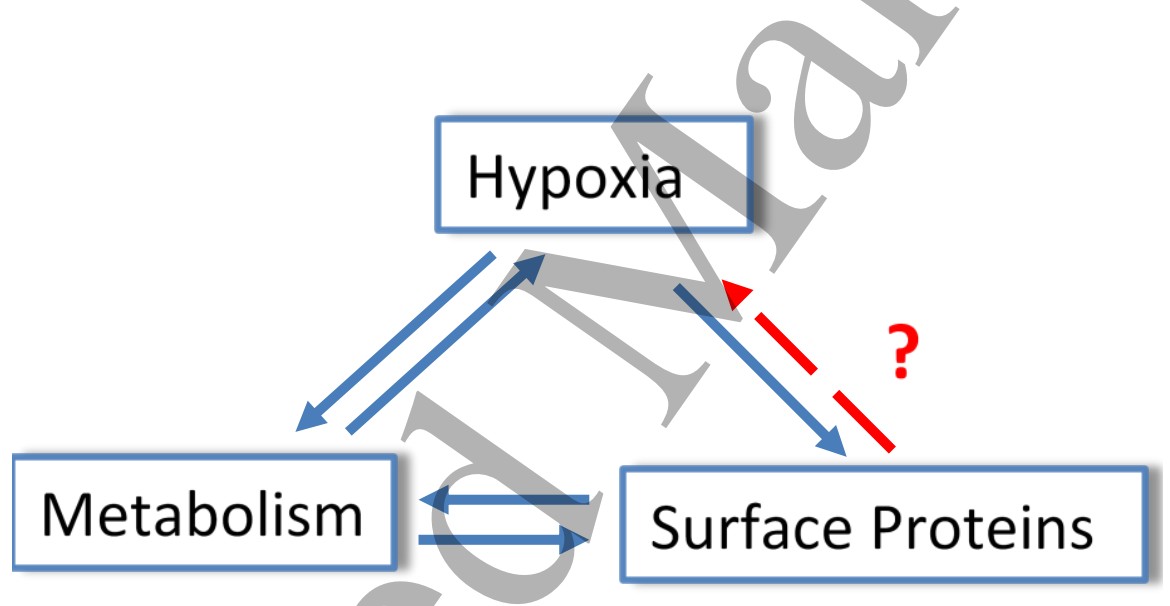


1

2

3

4

5

6

7

8

9

10

11

12

13

14

15

16

17

18

19

20

21

22

23

24

25

26

27

28

29

30

31

\section{Methods}

\section{Sample preparations}

Details of cell culture, surface characterization and RNA extraction have been reported previously [32]. Four surfaces (S1-S4) were synthesized and the tissue culture plate (Control) was prepared to culture hMSCs [32]. Briefly, the synthesized surfaces were prepared from poly(L) Lactic acid (PLA) material. Two flat surfaces (S1 and S2) were made by pressing PLA granules at $210{ }^{\circ} \mathrm{C}$ for 15 min using a portable hot press. Nonwoven fibrous matrices (S3-S4) were made by electrospinning (an in-house setup) a 7.5\% PLA solution. Subsequently, PLA substrates, both flat and fibrous (S2 and S4), were subjected to aminolysis reaction in $5 \%$ hexamethylenediamine solution $(\mathrm{w} / \mathrm{v}$, in isopropanol) for $30 \mathrm{~min}$ at $30^{\circ} \mathrm{C}$ under mild agitation, in order to introduce amine groups that alters the surface from hydrophobic to hydrophilic [57]. The flat PLA surface mimics a conventional two-dimensional cell culture plate surface topography, while, the fibrous PLA topography imitates the latest threedimensional cell culture matrix and/or native extracellular matrix architecture. The pristine PLA surface denotes a hydrophobic surface - typical of synthetic polymers, while, the aminated PLA surface signifies a hydrophilic surface - typical of natural polymers.

Human bone marrow-derived mesenchymal stem cells (hMSCs) (Lonza, UK) were incubated under $37{ }^{\circ} \mathrm{C}, 20 \%$ oxygen, $5 \% \mathrm{CO}_{2}$, with saturated humidity. The hMSCs were seeded onto the four different synthesized substrates (i.e. flat, pristine (S1); flat, aminated (S2); fibrous, pristine (S3); fibrous, aminated (S4)) at 50,000 cells per sample across $2 \mathrm{~cm}$ discs and cultured for 7 days with media changed at day 1 and then every other day. Standard tissue culture polystyrene substrate was used as control. Cell viability was measured at day 3,5 and 7 using the Alamar blue based non-destructive assay (Thermo Scientific, UK). A standard curve was prepared by taking known concentration of cells in serial dilutions. The absorbance of the test samples was compared with the standard curve in order to convert absorbance values into cell number. Total RNA from each sample was extracted with the RNeasy Mini Kit (Qiagen, UK). NanoDrop UV/VIS spectrophotometer (1000, Thermo Scientific) and RNA agarose gel electrophoresis methods were used to assess the quality and quantity of the total extracted RNA [32],

\section{Sequencing data analysis}

RNA sequencing was completed on the Day 3 samples. The sequencing experiment and the upstream bioinformatics pipeline has been reported previously [32], further analysis and additional tests were done in this study. Genes with over $100 \%$ change in their expression levels against control, 
and a false discovery rate less than 0.001 were considered to be differentially expressed (DEG). A threshold of expression level (FPKM >1) was set to filter out genes with low abundance.

3

\section{Analysis of hypoxia-regulated genes}

The gene set describing the HRG was obtained from an online database (HypoxiaDB, www.hypoxiadb.com) [58]. The transcriptome datasets of the five samples (NCBI sample number: SRS2493619; SRS2493628; SRS2493629; SRS2493630; SRS2493885) were compared and analysed for the HRG. Hierarchical cluster analysis compared the gene expression profile for the ensemble HRG between samples.

A list of the hypoxia-altered surface proteins in hMSCs were compiled from the literature database and checked against the detected expressions in this study. Gene expression correlation and cluster analysis were both conducted with the criteria of Pearson coefficient $(R)>0.9$ or $<-0.9$ and $p$ $<0.01$.

The genes encoding hMSCs surface proteins were obtained from the compiled literature surface proteome [59-61]. Pathway enrichment analysis and the identification of functional gene sets (e.g., genes involved in each cell cycle stages) were conducted utilizing the KEGG database [62]. Gene ontology was done using the DAVID database [63].

\section{Quantitative real-time PCR}

RNA extracted from the Day-5 samples were used for qRT-PCR testing of expression levels of HIF2A (also known as EPAS). The RNA samples were reversely transcribed, with a genomic DNA wipeout step, using the QuantiTect Reverse Transcription Kit (Qiagen, Stanford, USA) according to the manufacturer's instructions. Quantitative real-time PCR (qRT-PCR) was performed using Rotor-Gene 6000 (Qiagen, Stanford, USA), with the following cycle parameters: enzyme activation at $95^{\circ} \mathrm{C}$ for 2 min, 40 cycles of denaturation for 5 seconds of $95^{\circ} \mathrm{C}$ followed by $60^{\circ} \mathrm{C}$ for 25 seconds. The fluorescence acquisition was performed with the SyGreen Blue Mix Lo-ROX (Pcrbiosystems, UK) following the manufacturer's instructions. 3 repeats were run for each sample-gene pair. The fold change was calculated using the delta-delta-Ct method with GAPDH as the reference gene. The primers were designed using Primer-BLAST (ncbi.nlm.nih.gov/tools/primer-blast/) and ordered from Sigma, UK. The tested primer sequences are listed below as: HIF2A-f: GCGCTAGACTCCGAGAACAT; HIF2A-r: TGGCCACTIACTACCTGACCCTT; GAPDH-f: GGATTTGGTCGTATTGGG; GAPDH-r: GGAAGATGGTGATGGGATT. 
1

2

3

4

5

6

7

8

9

10

11

12

13

14

15

16

17

18

19

20

21

22

23

24

25

26

\section{Results}

hMSCs were cultured on 5 different surfaces for 3 days before total RNA was extracted and processed for NGS. The overall sequencing quality was confirmed by mapping the saturation and distribution of the reads [32]. A total of 2,147 HRG were detected, with 1,873 genes exceeding a threshold expression level (Supplementary Information table S1). The HRG were analysed, to examine their dependency on culture surface conditions, unless otherwise specified.

\section{Cell culture data}

The samples seeded on different culture surfaces resulted in significant differences in growth rate over the culture period, as shown in Figure 2. The control surface supported the fastest proliferation rates and had a much shorter lag phase compared to the cells cultured on the synthesized surfaces (until day 3). Compared to the samples cultured on flat surfaces (S1 and S2), fibrous surfaces (S3 and S4) resulted in higher levels of growth suppression and resulted in the slowest growth rate. The modification of surface chemistry induced negligible changes on cell growth. Readers interested in cell culture and material characterization data can refer to the Supplementary Information or our earlier work [32].

Key cell cycle regulators and hallmark genes involved in different cell cycle stages were analysed (Supplementary Information table S2). Despite the treated samples experienced slower growth rate than the Control, several positive cell-cycle regulating genes were up-regulated, including CCND1, CCNE2, CCNB2, E2F1. Meanwhile, some other genes involved in cell cycle progression were found to be down-regulated, e.g. TGFB2, INHBA, THBS1, etc. The genes involved in the G1 phase were relatively stable with only 2 genes (CDC6 and TBRG4) changing by more than 50\%; none of the G1 phase genes were highly expressed. No genes involved in the $\mathrm{S}$ phase transition was differentially expressed. Contrastingly, the expression levels of 7 genes involved in regulating the $M$ phase (AURKA, MAD2L1, KPNA2, TGFB1, PPP5C, NOLC1, PAM) were significantly altered, suggesting a greater variation during phase progression between samples which may have contributed to the observed differences in cell growth rate, as shown in Figure 2. 


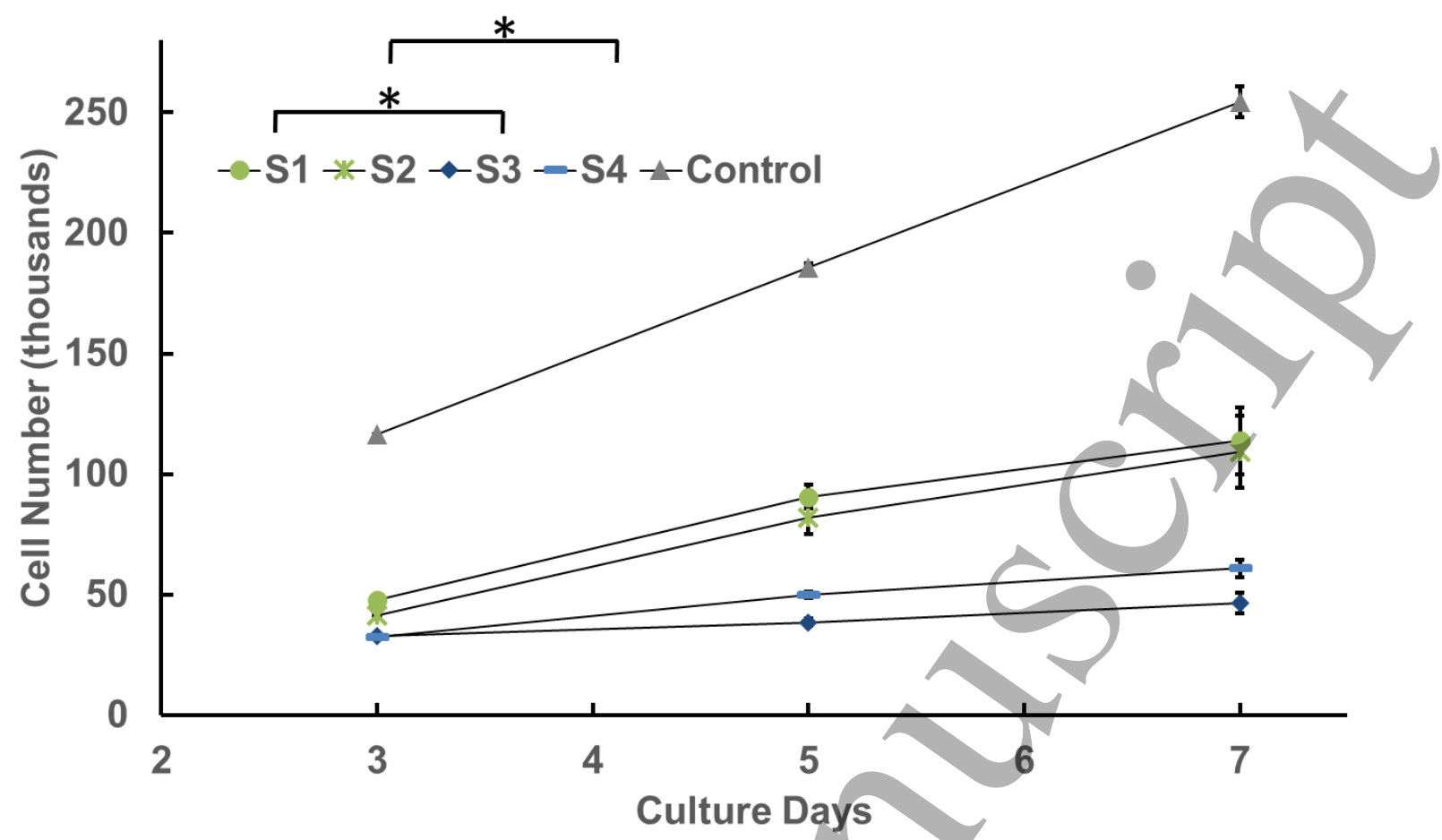

1

Figure 2: Cell growth data for samples cultured on the five different surfaces. The cell number (mean) on each day is represented with standard error. The difference between the Control and the treated samples are statistically different $(p<0.001)$. The difference between S1 and S3, and S2 and S4 are also statistically different (marked with asterisk) $(p<0.001)$. Figure adapted from data presented in [32].

\section{Sample variations of HRG expression levels}

The expression variations of HRG across the different samples are shown in Figure 3. Samples with similar expression patterns and small Euclidean distances were paired. The HRG expression profile of the cells cultured on the synthesized surfaces exhibited a significant difference compared to the control sample. Small expression variations were observed between S1 and S2, and between S3 and S4, the two pairs were cultured on flat and fibrous surfaces, respectively. As described previously 12 for all genes [32], the alteration of the surface topography resulted in a greater impact on cell HRG expression profile than the changes made on surface chemistry. Similar markers (e.g., frequency of gene expression levels, the distribution of coefficient of variation, etc.) were found to be comparable between the HRG and the complete transcriptome profile. 


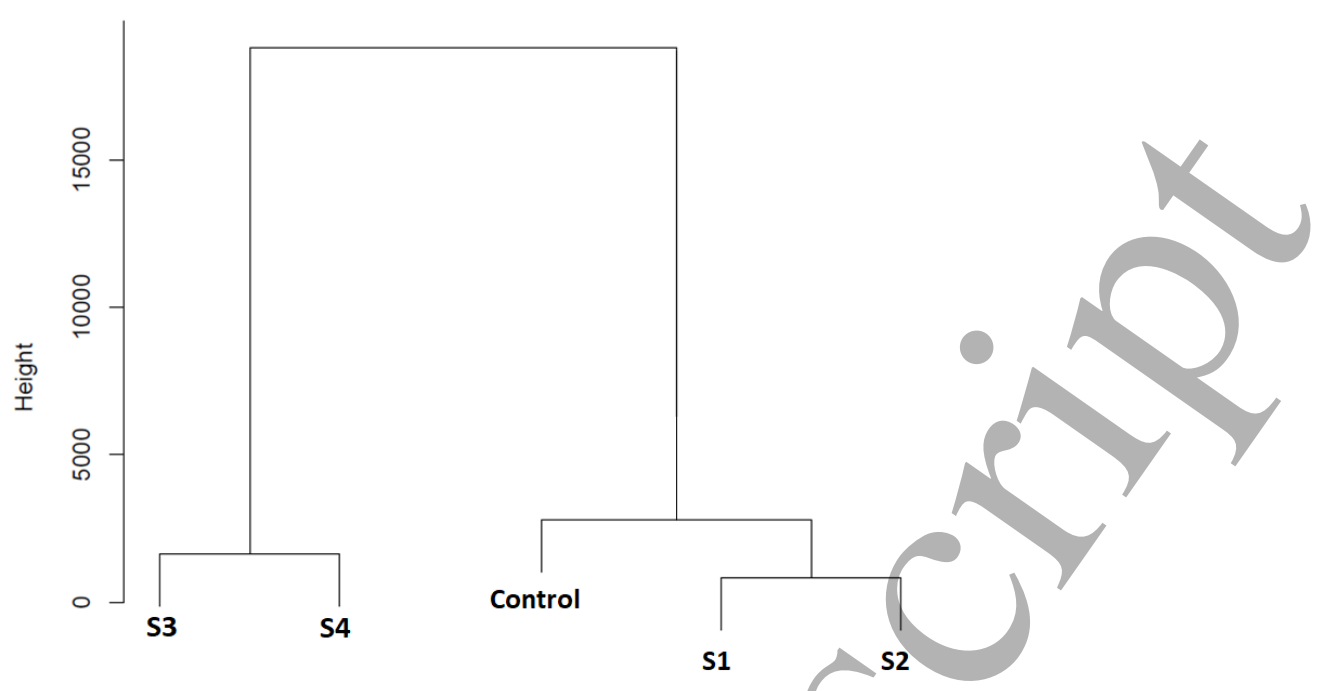

1

2

4

5

6

7

8

9

10

11

12

13

14

15

16

Figure 3: Dendrogram representing hierarchical cluster distributions of the samples cultured on the four synthesized surfaces and Control for the 1,873-detected hypoxia-regulated genes. The Euclidean distance is shown on the vertical axis.

Samples with smaller pairwise difference is grouped together.

\section{Compiled expression of oxygen-sensitive surface proteins}

In the literature, various surface proteins were affected by in vitro hypoxic cell culture. It is important to determine whether the expression of these proteins were altered in this study. A list of 15 reported hypoxia-altered surface proteins in hMSCs is shown in Table 1, their respective expression levels from samples in this study are shown. The expression levels for six of these genes, i.e., CD93, PLCAP, ESAM, SMOC2, CDH and PLEKHA6, were below the threshold for further analysis in all samples.

11 The measured level of ITGB1 and ITGA5 were consistently detected.

Table 1: The compiled expression of surface proteins which were altered under in vitro hypoxia. The expression of the two hypoxic hallmark genes, HIF1A and HIF2A (EPAS) are also shown. The measured gene expression levels from the control (C) and the four synthesized surfaces are reported. Up-and down-regulated genes are highlighted in green and red, respectively. The Pearson coefficient $(R)$ and $p$ values for the expressions of each gene are shown.

\begin{tabular}{|rlllllllll|}
\hline Entrez ID & Gene & $R$ & $p$ & S1 & S2 & S3 & S4 & C & Ref. \\
\hline 83483 & PLVAP & - & - & - & - & - & - & - & {$[16]$} \\
90952 & ESAM & - & - & 0 & 0.1 & 0 & 0.1 & 0.1 & {$[16]$} \\
22918 & CD93 & - & - & 0 & 0 & 0 & 0 & 0 & {$[16]$} \\
22874 & PLEKHA6 & - & - & 0.1 & 0.1 & 0 & 0.1 & 0.3 & {$[16]$} \\
64094 & SMOC2 & - & - & 0 & 0.2 & 0 & 0 & 0 & {$[16]$} \\
999 & CDH & - & - & 0.2 & 0 & 0 & 0 & 0.1 & {$[64]$} \\
\hline 3688 & ITGB1 & -0.62 & 0.26 & 788 & 802 & 943 & 834 & 820 & {$[64]$} \\
7412 & CD106 & 0.89 & 0.04 & 10.1 & 13.2 & 7 & 10 & 24.2 & {$[16]$} \\
1000 & N-CAD & 0.97 & 0.01 & 69.6 & 75.1 & 44.9 & 52.5 & 83.7 & {$[64]$} \\
3693 & ITGB5 & -0.62 & 0.26 & 144 & 126.3 & 127 & 128 & 88 & {$[64]$} \\
3678 & ITGA5 & -0.83 & 0.08 & 165 & 135.9 & 192 & 159 & 121 & {$[64]$}
\end{tabular}




$\left.\begin{array}{|llllllllll|}3673 & \text { ITGA2 } & -0.86 & 0.06 & 2.9 & 3.3 & 6.9 & 4 & 1.7 \\ 2335 & \text { FN1 } & -0.83 & 0.08 & 7149 & 7037 & 15,579 & 14,297 & 8124 & {[64,} \\ 3690 & \text { ITGB3 } & -0.93 & 0.02 & 5.6 & 5.4 & 17.8 & 13.9 & 3.3 & {[64]} \\ 6387 & \text { CXCL12 } & 0.42 & 0.48 & 82.4 & 78.9 & 45.4 & 44.2 & 53.4 & {[65]} \\ \hline 3091 & \text { HIF1A } & -0.83 & 0.08 & 140 & 169 & 186 & 184 & 148 & - \\ \hline & \text { HIF2A } & 1 & 0 & 137 & 135 & 48.3 & 56.8 & 214\end{array}\right]$

1

The two hypoxic hallmark genes, HIF1A and HIF2A (EPAS) were detected in all samples in this study, with HIF1A being consistently expressed. HIF2A was down-regulated in cells cultured on the synthesized surfaces, including a 4-fold decrease in samples cultured on fibrous surfaces, similar to the trend for $N-C A D$. Interestingly, the remaining eight genes exhibited large expression variations across samples. The genes with up- or down-regulation of greater than 1.5-fold change are highlighted in green and red in Table 1, respectively. The samples cultured on fibrous surfaces, were found with significantly higher expressions of ITGA2, ITGB3 and FN1, than the control. Conversely, N-CAD, a differentiation marker [66-68] was found to be reduced by 50\%. CXCL12, a chemokine to increase hMSCs homing and the interaction with hematopoietic stem cells $[69,70]$, was detected with a 2-fold increase in samples cultured on flat surfaces over those on fibrous surfaces. The expression level of a typical MSCs marker, CD106, was found to be supressed in all samples cultured on the synthesized surfaces, whereas, ITGB5 was found to be consistently upregulated.

In the reported literature data, a few of these genes were found to be altered by hypoxia. In Mathew et al., expression levels of FN1, N-CAD, ITGB1, ITGB3, ITGB5, CDH1, and ITGA2 were reported with 1.5 - to 2.5 -fold increase in hypoxic culture; the increase with CDH1 and ITGA2 were not statistically significant [64]. The increase in the hypoxic expression of FN1 and CXCL12 was also reported [65]. The signal measured via flow cytometry for CD106 was greater in 1.5\% oxygen culture condition. The induced fold change, because of in vitro hypoxia, is in a similar magnitude as induced by culture surfaces in this study.

\section{HIF2A is regulated by surface proteins}

Table 1 compiled the reported hMSCs genes which encode surface protein and are sensitive to culture oxygen tension. This study utilized the NGS to show a change in culture surfaces could also alter the expression levels of genes encoding these oxygen-sensitive surface proteins. The expression level of HIF2A, a hallmark hypoxic gene, was measured to be significantly down-regulated. From the 
results reported in the literature $[71,72]$ and from this study, HIF $2 \alpha$ is hypothesized to be a key mediator in both regulating and being regulated by different surface proteins.

The Pearson coefficient $(R)$ and the $p$-value across the samples are also presented in Table 1. Expression levels of CD106 and N-CAD were found to be statistically significant and positively correlated with the expression profile of HIF2A across the tested samples, which may suggest a direct up- or downstream regulation between the two and HIF2A. The positive correlation between CD106 and $\mathrm{N}$-CAD expression was reported by Aomatsu et al. [73]. In their study, the overexpression of $\mathrm{N}$ $C A D$ was able to rescue the suppressed expression of $C D 106$, and the overexpression of a dominant negative $N-C A D$ reduced the level of $C D 106$. Yamashita et al. discovered the direct regulation of HIF2A on CD106 via HIF2A knockdown and chromatin immunoprecipitation assays [71]. The downregulation of CD106 expression is therefore hypothesized to occur downstream to that of HIF2A and N-CAD. Leonel showed that the secretion of VEGF, a downstream HIF2 $\alpha$ target, significantly increased after the incubation of bone-marrow derived MSCs with additional N-cadherin in the solution [74]. Despite the results demonstrated by Leonel, no direct gene expression level correlation between N-CAD and HIF2A has been reported, it remains to be elucidated that whether $N-C A D$ is altered upstream to HIF2A.

Additionally, N-CAD has been reported to regulate the differentiation potential of MSCs [7578]. Liu et al. found that the expression level of $C D 106$ was greatly reduced after differentiation while the expression levels of other MSCs markers remained stable [79]. HIF2A has been reported to contribute to the maintenance of cell pool stemness [80, 81]. CD106 and N-CAD may contribute to the regulation of cell pool potency via pathways involving EPAS (HIF2A). Additionally, the high CD106 expressing population of MSCs have demonstrated strong elevated angiogenic capacity with numerous marker genes and produced cytokines being significantly upregulated [82].

On the other hand, ITGB3 (CD61) negatively correlated with the expression of HIF2A (Table 1). Various studies have found that ITGB3 has a regulatory potential in controlling tumour growth and angiogenesis, whereas the inhibition of ITGB3 has reduced cellular angiogenic potential [83-87]. Furthermore, we found that the expression of VEGFA was found to be positively correlated with ITGB3, showing a negative correlation with that of HIF2A. In the first 3 days of culture, other pathways may be the more dominant factors in affecting the expression of VEGF other than HIF2A. Kracun et al. reported the overexpression of the ITGB3 protein receptor, $\beta 3$-endonexin, was found to negatively regulate the expression of HIF1a mRNA under hypoxia; HIF2 $\alpha$ protein, however was not affected [88]. Therefore, incorporated with the findings from this study, the surface-induced negatively correlated 
1 ITGB3 expression, may be a result of the downstream HIF2A regulation. The impact of ITGB3 on MSCS

2 have not been reported; its reported functions in regulating growth and angiogenesis in tumour cells $3[89,90]$ are expected to be analogous to those in MSCs.

Martin et al. reported that HIF2 $\alpha$ binds to the promoter of CXCL12 under hypoxia and may be 5 used to regulate angiogenesis [91]. HIF2 $\alpha$ has been observed to induce FN1, which also regulates 6 cytoskeleton arrangement, under hypoxia in lung cancer endothelial cells [92], and melanoma cells 7 [93]. A partial impact of HIF2A on ITGB1 and ITGA5 was reported by Hughes et al. in cancer cell lines 8 [94]. The four types of synthesized surfaces selectively altered the expression of HIF2A and the gene 9 expression profile, which may in turn, differentially regulate the respective downstream hypoxic signalling pathways and functions. From the experimental data reported in the literature and this study, the change in HIF2A expressions is hypothesized to be the result of different activated surface proteins.

\section{Mapping HIF2A correlated genes and functions}

In order to infer how the synthesized surfaces altered the HRG, four gene sets were studied, including the genes encoding hypoxia-sensitive surface proteins (Table 1), all detected HRG, hMSCs cell surface proteome markers [59-61] and the detected genes from this study that are correlated to the expression of HIF2A. 573 genes were found to be correlated with the expression of HIF2A (full details shown in Supplementary table S3). Figure 4 shows the number of unique and shared genes from the four gene sets. The genes that are shared by three sets are listed in the diagram, e.g. hypoxiaregulated and HIF2A-correlated surface proteins: CD47, HM13, COL6A1, TGFBR1, CD44, and PVR. This finding provides insights for future studies to validate specific gene and pathway interactions between the interaction of surface and hypoxia signalling. 


\section{HIF2A correlated genes Hypoxia-regulate genes}

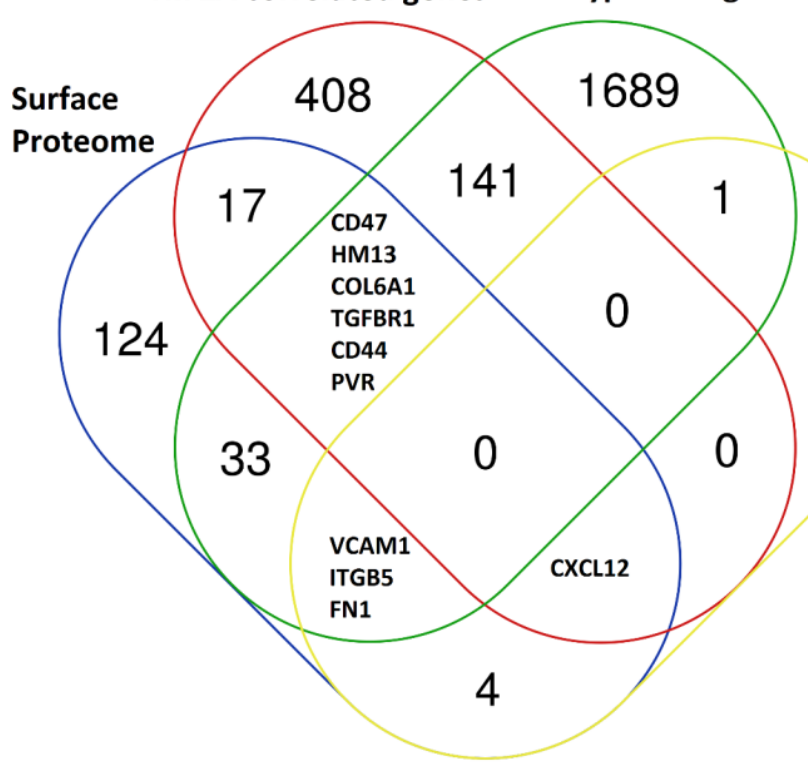

Figure 4: Venn diagram indicating the number of shared genes between the fourgene sets. The genes with the expression levels correlating with that of HIF2A in samples cultured on the five surfaces, the detected hypoxia-regulated genes, genes encoding hMSCs surface proteome and the literature reported oxygen-sensitive surface proteins. surface proteins

Across the samples cultured on the five types of surfaces, 1,873 of the 2,289 HRG were detected. These HRG significantly enriched key signalling, adhesion, and cancer related pathways, e.g., FoxO, PI3K-Akt, MAPK and HIF1A signalling, focal adhesion, cell cycle, colorectal, pancreatic cancer and leukaemia pathways (Table 2). 102 HRG were found to be differentially expressed in more than two sets of surfaces, demonstrating the effective alteration in the expression of HRG (Supplementary Information table S4).

Among the genes encoding the 15 oxygen-sensitive surface proteins in Table 1, only VCAM1, ITGB1, CXCL12 and FN1 were both detected in our samples and reported in the hypoxia database. The other four detected genes encoding integrin subunits were not found in the database; among the six undetected genes, only $\mathrm{CD} 93$ was referenced to be regulated by hypoxia.

Comparing with the expression levels of HIF2A across samples, 321 positively and 252 negatively correlated genes were found. N-CAD, a hypoxia-sensitive differentiation marker, positively correlated with the expression of HIF2A with a 1.5-fold expression reduction in the samples cultured on fibrous surfaces. 147 of the correlated genes were found to be also regulated by hypoxia (Supplementary Information table S5), and 24 genes were detected in the hMSCs surface transcriptome (Supplementary Information table S6); CD44, CD47, HM3, COL6A1, TGFBR1 and PVR were found in both lists. Figure 5A shows the gene ontology results for the 37 correlated HRG (with the legend shown in Figure 5B) contributing to the functions of extracellular matrix organization, cell 
1 adhesion, regulation of hypoxia, growth, and angiogenesis; the six HRG classified to negatively

2 regulate angiogenesis were all found to positively correlate to the expression of HIF2A (Figure 5C).

3 CCL2 and COL4A2 were reported to be in both the positive (GO:0001525) and negative (GO:0016525)

4 regulation of angiogenesis.

Certain correlated genes were differentially expressed across the samples cultured on

6 different surfaces. 33 and 17 DEGs were found in the positively and negatively correlated genes,

7 respectively. The induced signalling responses from the culture surfaces are more pronounced on the

8 expression of certain genes, significantly up- or down-regulate their expression. Two pathways were

9 found to be significantly enriched by these DEGs, i.e. Hippo signalling pathway, and the pathways in

10 cancer. The genes encoding two surface proteins, LGALS3 and TFGBR1, were differentially expressed.

Table 2: Gene ontology analysis for the HIF2A-correlated and hypoxia-regulated genes. The number of genes and the percentage of the genes found in the function is reported. The statistical $p$ values and q values (Benjamin) are shown.

\begin{tabular}{|l|l|r|r|r|l|}
\hline Functions & G.O. Number & Gene Count & $\%$ & $p$ & $q$ \\
\hline Extracellular matrix organization & 0030198 & 14 & 9.5 & $1.40 \mathrm{E}-08$ & $1.80 \mathrm{E}-05$ \\
\hline Cell adhesion & 0007155 & 15 & 10.2 & $4.10 \mathrm{E}-05$ & $2.70 \mathrm{E}-02$ \\
\hline Regulation of cell growth & 0001558 & 7 & 4.8 & $6.40 \mathrm{E}-05$ & $2.80 \mathrm{E}-02$ \\
\hline Response to hypoxia & 0001666 & 9 & 6.1 & $1.20 \mathrm{E}-04$ & $3.80 \mathrm{E}-02$ \\
\hline Angiogenesis & 0001525 & 10 & 6.8 & $1.30 \mathrm{E}-04$ & $3.40 \mathrm{E}-02$ \\
\hline Negative regulation of angiogenesis & 0016525 & 6 & 4.1 & $1.90 \mathrm{E}-04$ & $4.10 \mathrm{E}-02$ \\
\hline
\end{tabular}
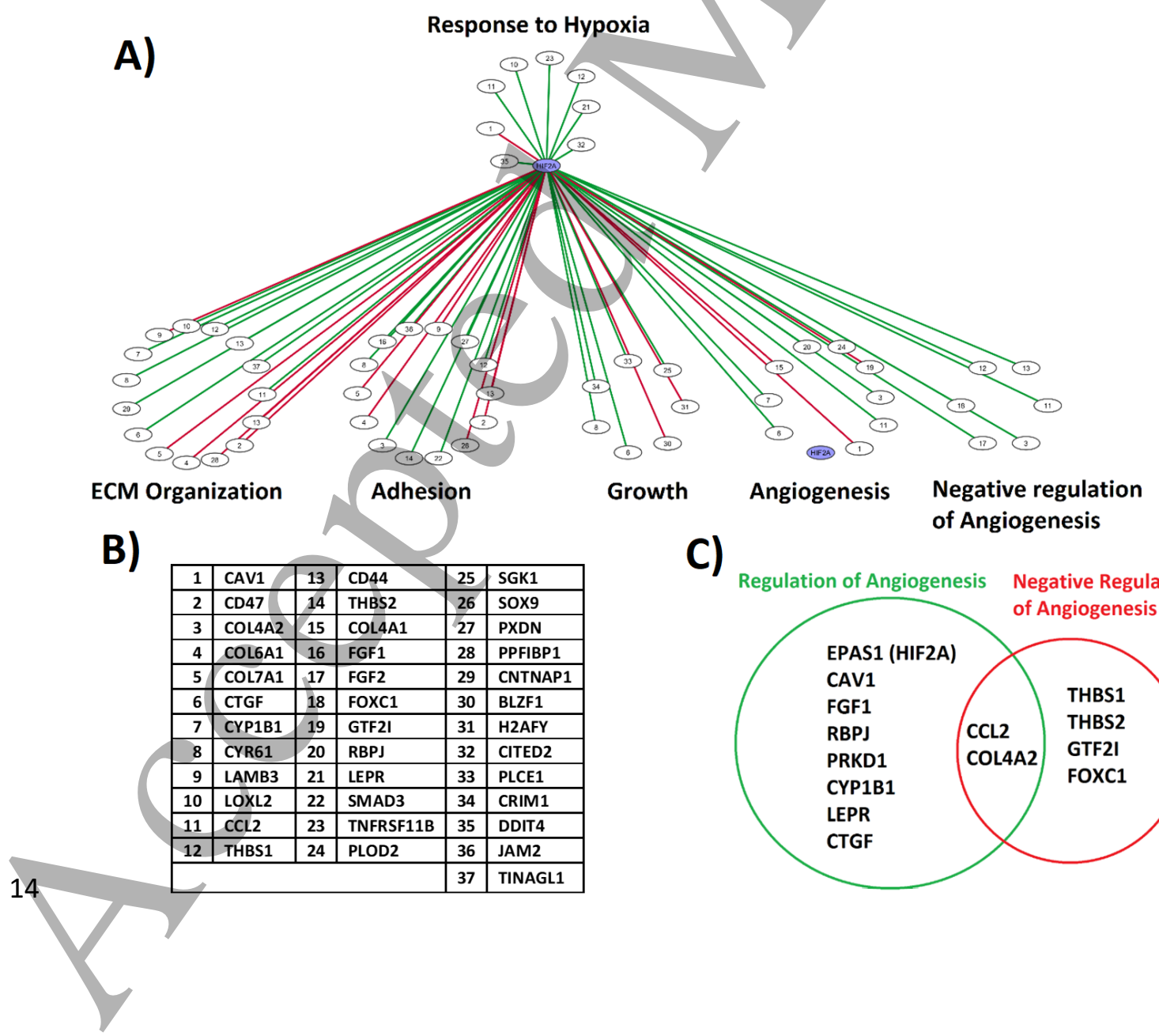

C)

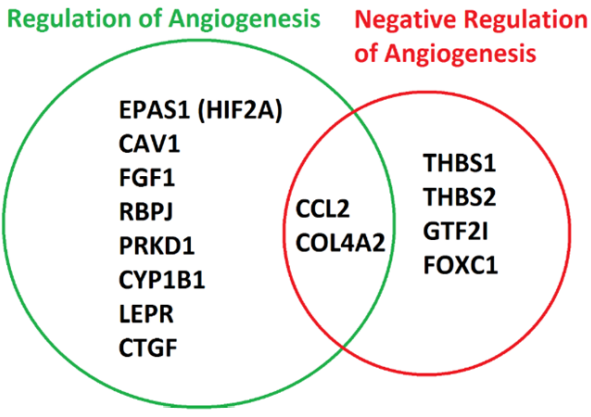


Figure 5: HIF2A-correlated and hypoxia-regulated genes. A) The 37 positive and negative correlations are shown in green and red, respectively. Different functions from gene ontology analysis are labelled, and each unique gene is numbered with the gene names shown in B). The genes reported for the positive and negative regulation of angiogenesis are shown in part C).

\section{Quantitative PCR validation of HIF2A expression}

Quantitative PCR was performed to confirm the trend observed in the sequencing results using Day-5 samples. The Ct values and the fold change for EPAS (HIF2A) against Control are shown in Figure 6 . The reduced expression of HIF2A on the synthesized surfaces was confirmed with qRT-PCR.

A modest down-regulation in S1 and S2, and a significant down-regulation in S3 and S4 samples were confirmed for, as previously shown in Table 1. The comparable results between NGS and qPCR using Day-3 and Day-5 samples, respectively, demonstrated stable down-regulation of EPAS (HIF2A) expression on fibrous surface.

\section{Discussion}

Hypoxic cell culture has exhibited outstanding impacts on the rate of proliferation, stemness,

Figure 6: Quantitative real-time PCR results showing the Ct values (A) and the relative fold change of the samples compared to the Control (B), $n=3$. The results from RNA sequencing, is shown for each sample-gene pair.
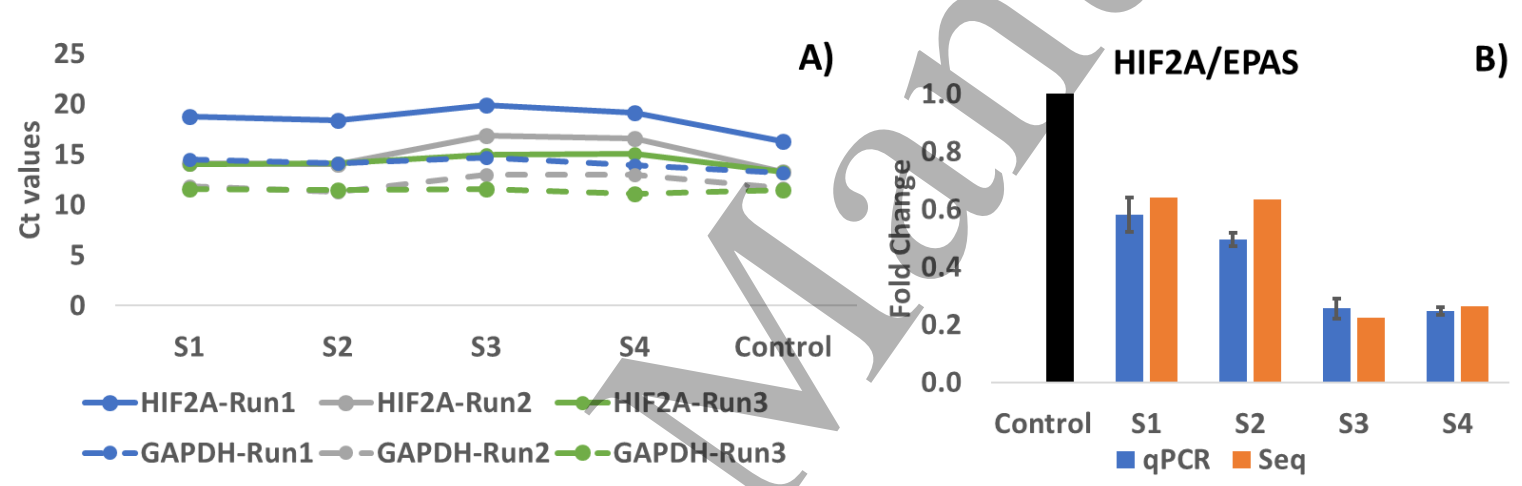
27 expressions to address this challenge. The change in the HRG expression in the hMSCs cultured on the 28 four different synthesized surfaces were examined. By addressing this missing link, it may shed insights 29 into addressing some controversies on the effects of hypoxia on MSCs. In addition, certain HRG and 
hypoxia-regulated pathways may be selectively enhanced or suppressed by different culture surfaces. Certain benefits from in vitro cell culture may be specifically induced without subjecting cells to a hypoxic environment.

In this study, the hMSCs cultured on four different surfaces were analysed for the induced HRG and enriched pathways. The expression levels of several key hypoxia functional genes were significantly altered, e.g. HIF2A, VEGFB, THBS1, etc. Various surface proteins and their encoded genes may have enacted upstream of HIF2A, which led to the regulation of HIF2A, as shown in Figure 7; CD106 is hypothesized to be downstream of HIF2A and NCAD. This finding suggests the effect of surface protein activations on oxygen-sensing/hypoxia-regulating pathways, providing supporting evidence and encouraging future studies to fill the missing knowledge gap in Figure 1 . HIF2A is hypothesized to play a key intermediate role in linking the surface sensing and hypoxic response pathways.

The expression level of HIF1A was comparable across different samples. The capacity of HIF1 $\alpha$ in responding to different oxygen levels and regulating hypoxic functions are carried out at the protein level, its gene expression is expected to be relatively stable [97-99]. Different experiments in the literature have reported that HIF2 $\alpha$ protein is less sensitive to the protein-level degradation as HIF1 $\alpha$ $[80,100,101]$, therefore, a change in its gene expression is expected to be reflected at the protein level. Different stem cell markers and the rate of proliferation have been traced back to HIF2A activity [102-106]. This study observed the reduction in HIF2A gene expression in hMSCs cultured on all the synthesized surfaces. Alterations in pluripotency and differentiation markers were also observed in a surface-dependent fashion. The variation in these markers was selective to specific surfaces, which may have contributed to some controversial observations on their differentiation capacities [3, 13-16, 107]. 


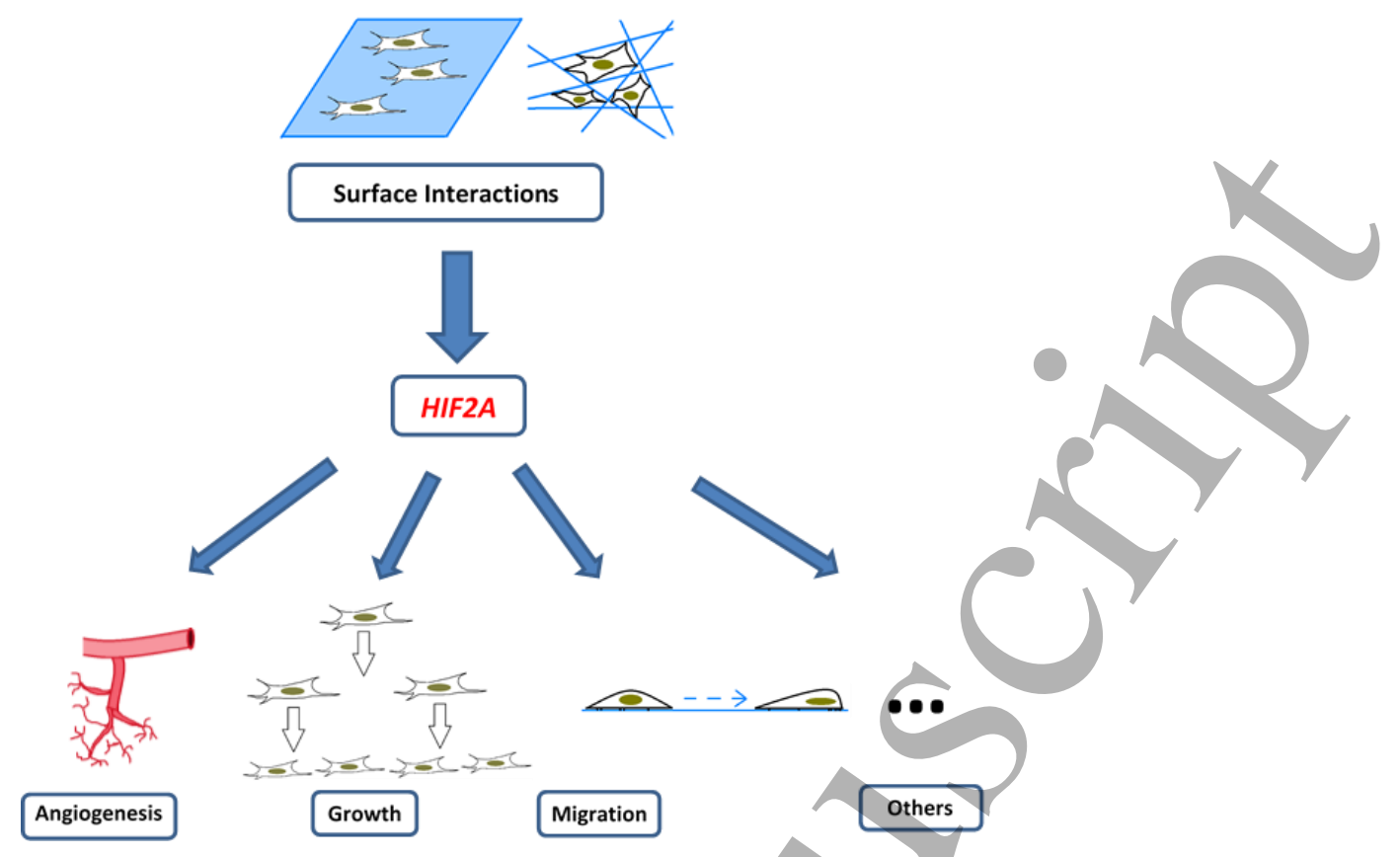

Surface Interactions

Figure 7: A hypothesis of HIF2A-regualted functions in the hMSCS cultured on different culture surfaces.

A list of the 2,289 oxygen-sensitive genes was analysed in this study. Their dependency on oxygen tension may originate from their roles in the various oxygen sensing pathways. This study detected 1,873 of these genes, some of which demonstrated strong dependency to the culture surfaces hMSCs adhered to. Outstanding differences were observed for ITGA2, FN1, ITGB3, and CXCL12, in samples cultured on both fibrous and flat surfaces. The expressions of the genes encoding various hypoxia-regulated surface proteins were found to be closely related to that of $H I F 2 A$. Considering of the reported oxygen-sensitive surface proteins, this study found that culture surfaces regulate the gene expression of various surface proteins, some of which subsequently alter the expression of HIF2A and its downstream functions. Culture surfaces triggered part of the oxygen sensing and its downstream signalling pathways.

This study found HIF2A to be regulated by a change in activated surface proteins. The analysis of HIF2A expression across the samples cultured on different surfaces yielded 573 genes with significant expression correlations (Supplementary table S3), 147 of which have been reported with regulation dependency to hypoxia (Supplementary table S5). Among the correlated genes, the DEGs showed outstanding differences between the compared samples, including genes encoding hMSCs surface proteins. The significant reduction in the HIF2A gene expression in the samples cultured on fibrous surfaces (Table 1 and Figure 6) was induced by their surface topography, which regulated the expression of certain genes encoding surface proteins and led to the downstream alteration on HIF2A. Subsequently, HIF2A was transcribed and translated to regulate various crucial functions in hMSCs, such as survival [7]. Gene ontology analysis revealed the functions associated with the correlated HRG, 

including regulation on cell growth, hypoxic functions, angiogenesis, and cell surface interactions. HIF2A activity has been reported to promote hMSCs growth $[101,108]$; in this study, the change in the measured HIF2A expression levels (Table 1 and Figure 6) is in line with the observed trend of cellular growth rate (Figure 2).

5

The rate of degradation of PLA was not expected to be significant in this experiment. All material was handled under the suggested conditions [109]. Therefore, the $\mathrm{pH}$ in culture medium was not expected to be affected by PLA degradation and the subsequent reduction of cell proliferation. No change in media colour was observed. In addition, culture media was changed every alternative day to reduce the impact of material degradation and to ensure the availability of metabolites and growth factors. Furthermore, with the moderate cell density, oxygen tension was not expected to be significantly different for the hMSCs cultured on different surfaces. The change in the expressions of HRG was considered to be independent of oxygen tension.

In storage, transportation, and therapeutic applications, maintaining a consistent hypoxic environment may be challenging, research has shown short-term exposure to normoxia can result in lasting changes $[65,110]$. The findings from this study showed the possibility of using specially designed culture surfaces in regulating HRG and pathways in hMSCs under in vitro normoxia. A few other studies have reported on the altered gene expressions induced by culture surfaces $[37,111$ 115]. Furthermore, in vitro hypoxia and culture surface may interactively affect the regulation of surface proteins and their downstream pathways. This effect may have contributed to some contrasting results when comparing hypoxic experimental data from different research groups. Lastly, fibrous surfaces induced a more complex array of pathways which could play a major role in further reducing cellular growth rate. In vitro rate of proliferation dictates the required time for a large-scaled hMSCs production, it is important to establish a set of culture conditions (hypoxia, culture surfaces, etc.) which can optimize the process. Novel surfaces can be designed to up- or downregulate HIF2A and its downstream functions such as angiogenesis, cell migration, growth, etc. The preservation of hMSCs also need to be monitored during culture, hypoxia has been reported to effectively manage the process; specialized surfaçes can be designed to reverse the undesired tendency. Future research will investigate on the potential of utilizing hypoxia and culture surfaces to collectively regulate hMSCs status. 
1

2

3

4

5

6

7

8

9

10

11

12

13

14

15

16

17

18

19

20

21

22

23

24

25

26

27

28

29

30

31

\section{Conclusions}

The results from RNA sequencing demonstrated that culture surfaces play a role in altering the expressions of HRG and hypoxia-regulated pathways. The sensitivity of the incurred effects was found to be pathway and surface specific. Expression levels of key hypoxic functional genes were altered because of a change in culture surface. Fibrous surfaces induced more hypoxia regulated DEGs which encoded a complex array of cellular functions and resulted in slower rates of proliferation than hMSCs cultured on flat surfaces. The expression levels of several oxygen-sensitive surface proteins were found to be affected by a change in culture surfaces, some of which are hypothesized to act upstream of HIF2A and subsequently modulated its expression. Culture surfaces with different substrates hold great potential towards designing surfaces to selectively activate hypoxia-induced pathways under in vitro normoxia or to enhance specific functions under hypoxia.

\section{Acknowledgements}

We are grateful to China Regenerative Medicine International Limited, Hong Kong for funding this work. We extend our thanks to Prof. Ester Hammond for useful discussions and Dr. Michelle Kümin for proof-reading.

\section{Conflict of Interests}

The authors declare no conflict of interest. The funders had no role in the design of the study, in the collection, analyses, or interpretation of data, in the writing of the manuscript, and in the decision to publish the results.

\section{Availability of data}

All the processed data are presented in the manuscript or in the supplementary information. Information on raw data and materials are available from the NCBI BioProject number PRJNA395968 and from the corresponding authors upon request.

\section{References}

1. Tsai, C.-C., et al., Hypoxia inhibits senescence and maintains mesenchymal stem cell properties through down-regulation of E2A-p21 by HIF-TWIST. Blood, 2011. 117(2): p. 459-

2. Haque, N., et al., Hypoxic culture conditions as a solution for mesenchymal stem cell based regenerative therapy. The Scientific World Journal, 2013. 2013.

3. Lee, J.-S., et al., Human bone marrow stem cells cultured under hypoxic conditions present altered characteristics and enhanced in vivo tissue regeneration. Bone, 2015. 78: p. 34-45. 
4. Tsai, C.-C., et al., Benefits of hypoxic culture on bone marrow multipotent stromal cells. Am J Blood Res, 2012. 2(3): p. 148-159.

5. Marycz, K., et al., Application of bone marrow and adipose-derived mesenchymal stem cells for testing the biocompatibility of metal-based biomaterials functionalized with ascorbic acid. Biomedical Materials, 2013. 8(6): p. 065004.

6. Estrada, J., et al., Culture of human mesenchymal stem cells at low oxygen tension improves growth and genetic stability by activating glycolysis. Cell Death \& Differentiation, 2012. 19(5): p. 743-755.

7. Zhang, S., et al., HIF-2 $\alpha$ and Oct4 have synergistic effects on survival and myocardial repair of very small embryonic-like mesenchymal stem cells in infarcted hearts. Cell Death \& Disease, 2017. 8(1): p. e2548.

8. Drela, K., et al., Low oxygen atmosphere facilitates proliferation and maintains undifferentiated state of umbilical cord mesenchymal stem cells in an hypoxia inducible factor-dependent manner. Cytotherapy, 2014. 16(7): p. 881-892.

9. Nicolaije, C., M. Koedam, and J.P. van Leeuwen, Decreased oxygen tension lowers reactive oxygen species and apoptosis and inhibits osteoblast matrix mineralization through changes in early osteoblast differentiation. Journal of cellular physiology, 2012. 227(4): p. 1309-1318.

10. Holzwarth, C., et al., Low physiologic oxygen tensions reduce proliferation and differentiation of human multipotent mesenchymal stromal cells. BMC cell biology, 2010. 11(1): p. 1.

11. Ren, H., et al., Proliferation and differentiation of bone marrow stromal cells under hypoxic conditions. Biochemical and biophysical research communications, 2006. 347(1): p. 12-21.

12. Tsai, C.-C., et al., Oct4 and Nanog directly regulate Dnmt1 to maintain self-renewal and undifferentiated state in mesenchymal stem cells. Molecular'cell, 2012. 47(2): p. 169-182.

13. Yang, D.-C., et al., Hypoxia inhibits osteogenesis in human mesenchymal stem cells through direct regulation of RUNX2 by TWIST. PloS one, 2011. 6(9): p. e23965.

14. Moriyama, H., et al., Role of notch signaling in the maintenance of human mesenchymal stem cells under hypoxic conditions. Stem cells and development, 2014. 23(18): p. 22112224.

15. Weijers, E.M., et al., The influence of hypoxia and fibrinogen variants on the expansion and differentiation of adipose tissue-derived mesenchymal stem cells. Tissue Engineering Part A, 2011. 17(21-22): p. 2675-2685.

16. Basciano, L., et al., Long term culture of mesenchymal stem cells in hypoxia promotes a genetic program maintaining their undifferentiated and multipotent status. BMC cell biology, 2011. 12(1): p. 1.

17. Guzy, R.D., et al., Mitochondrial complex III is required for hypoxia-induced ROS production and cellular oxygen sensing. Cell metabolism, 2005. 1(6): p. 401-408.

18. Kaelin Jr, W.G., ROS: Really involved in Oxygen Sensing. Cell Metabolism, 2005. 1(6): p. 357358.

19. Kim, J.H., et al., The pivotal role of reactive oxygen species generation in the hypoxia-induced stimulation of adipose-derived stem cells. Stem cells and development, 2011. 20(10): p. 1753-1761.

20. Williams, A.R. and J.M. Hare, Mesenchymal stem cells. Circulation research, 2011. 109(8): p. 923-940.

21. Thirumala, S., W.S. Goebel, and E.J. Woods, Manufacturing and banking of mesenchymal stem cells. Expert opinion on biological therapy, 2013. 13(5): p. 673-691.

22. Al-Nbaheen, M., et al., Human stromal (mesenchymal) stem cells from bone marrow, adipose tissue and skin exhibit differences in molecular phenotype and differentiation potential. Stem Cell Reviews and Reports, 2013. 9(1): p. 32-43.

23. Strioga, M., et al., Same or not the same? Comparison of adipose tissue-derived versus bone marrow-derived mesenchymal stem and stromal cells. Stem cells and development, 2012. 21(14): p. 2724-2752. 
24. Curtis, A. and M. Riehle, Tissue engineering: the biophysical background. Physics in Medicine \& Biology, 2001. 46(4): p. R47.

25. Jiao, Y.-P. and F.-Z. Cui, Surface modification of polyester biomaterials for tissue engineering. Biomedical Materials, 2007. 2(4): p. R24.

26. Palin, E., H. Liu, and T.J. Webster, Mimicking the nanofeatures of bone increases boneforming cell adhesion and proliferation. Nanotechnology, 2005. 16(9): p. 1828.

27. Lee, J., A.A. Abdeen, and K.A. Kilian, Rewiring mesenchymal stem cell lineage specification by switching the biophysical microenvironment. Scientific Reports, 2014. 4: p. 5188.

28. Murphy, W.L., T.C. McDevitt, and A.J. Engler, Materials as stem cell regulators. Nat Mater, 2014. 13(6): p. 547-557.

29. Cochis, A., et al., Bioreactor mechanically guided 3D mesenchymal stem cell chondrogenesis using a biocompatible novel thermo-reversible methylcellulose-based hydrogel. Scientific Reports, 2017. 7: p. 45018.

30. Hettiaratchi, M.H., R.E. Guldberg, and T.C. McDevitt, Biomaterial strategies for controlling stem cell fate via morphogen sequestration. Journal of Materials Chemistry B, 2016. 4(20): p. 3464-3481.

31. Walters, N.J. and E. Gentleman, Evolving insights in cell-matrix interactions: Elucidating how non-soluble properties of the extracellular niche direct stem cell fate. Acta Biomaterialia, 2015. 11: p. 3-16.

32. Li, Q., et al., Differential and interactive effects of substrate topography and chemistry on human mesenchymal stem cell gene expression. International journal of molecular sciences, 2018. 19(8): p. 2344.

33. Zhang B, K.N., Li Q, Ma J, Yang A, Cui Z, Wang H, Ye H., Effect of Substrate Topography and Chemistry on Human Mesenchymal Stem Cell Markers: A Transcriptome Study. International Journal of Stem Cells, 2019 (In Press).

34. Cukierman, E., et al., Taking Cell-Matrix Adhesions to the Third Dimension. Science, 2001. 294(5547): p. 1708.

35. Guvendiren, M. and J.A. Burdick, Stem Cell Response to Spatially and Temporally Displayed and Reversible Surface Topography. Advanced Healthcare Materials, 2013. 2(1): p. 155-164.

36. Phillips, J.E., et al., Human mesenchymal stem cell differentiation on self-assembled monolayers presenting different surface chemistries. Acta Biomaterialia, 2010. 6(1): p. 12-20.

37. Zhang, W., et al., The synergistic effect of hierarchical micro/nano-topography and bioactive ions for enhanced osseointegration. Biomaterials, 2013. 34(13): p. 3184-3195.

38. Wang, N., J.P. Butler, and D.E. Ingber, Mechanotransduction across the cell surface and through the cytoskeleton. Science, 1993. 260(5111): p. 1124-7.

39. Meinel, L., et al., Bone tissue engineering using human mesenchymal stem cells: effects of scaffold material and medium flow. Annals of biomedical engineering, 2004. 32(1): p. 112122.

40. Deschepper, M., et al., Survival and function of mesenchymal stem cells (MSCs) depend on glucose to overcome exposure to long - term, severe and continuous hypoxia. Journal of cellular and molecular medicine, 2011. 15(7): p. 1505-1514.

41. Kim, J.-W., et al., HIF-1-mediated expression of pyruvate dehydrogenase kinase: A metabolic switch required for cellular adaptation to hypoxia. Cell Metabolism, 2006. 3(3): p. 177-185.

42. Lavrentieva, A., et al., Effects of hypoxic culture conditions on umbilical cord-derived human mesenchymal stem cells. Cell communication and signaling, 2010. 8(1): p. 18.

43. Guo, S., et al., Glucose up - regulates HIF - 1 a expression in primary cortical neurons in response to hypoxia through maintaining cellular redox status. Journal of neurochemistry, 2008. 105(5): p. 1849-1860.

44. Ishizuka, T., T. Hinata, and Y. Watanabe, Superoxide induced by a high-glucose concentration attenuates production of angiogenic growth factors in hypoxic mouse mesenchymal stem cells. Journal of Endocrinology, 2011. 208(2): p. 147-159. 
45. Silva, M.M., et al., Robust expansion of human pluripotent stem cells: integration of bioprocess design with transcriptomic and metabolomic characterization. Stem cells translational medicine, 2015. 4(7): p. 731-742.

46. McMurray, R.J., Nanoscale surfaces for the long-term maintenance of mesenchymal stem cell phenotype and multipotency. 2011, University of Glasgow.

47. Saller, M.M., et al., Increased stemness and migration of human mesenchymal stem cells in hypoxia is associated with altered integrin expression. Biochemical and biophysical research communications, 2012. 423(2): p. 379-385.

48. Hung, S.P., et al., Hypoxia promotes proliferation and osteogenic differentiation potentials of human mesenchymal stem cells. Journal of Orthopaedic Research, 2012. 30(2): p. 260-266.

49. Song, H., et al., Reactive oxygen species inhibit adhesion of mesenchymal stem cells implanted into ischemic myocardium via interference of focal adhesion complex. Stem Cells, 2010. 28(3): p. 555-563.

50. Raheja, L.F., et al., Hypoxic regulation of mesenchymal stem cell migration: the role of RhoA and HIF - 1 a. Cell biology international, 2011. 35(10): p. 981-989.

51. Azevedo, M.M., et al., Hypoxia inducible factor-stabilizing bioactive glasses for directing mesenchymal stem cell behavior. Tissue Engineering Part A, 2014. 21(1-2): p. 382-389.

52. Mardis, E.R., The impact of next-generation sequencing technology on genetics. Trends in genetics, 2008. 24(3): p. 133-141.

53. Schuster, S.C., Next-generation sequencing transforms today's biology. Nature methods, 2008. 5(1): p. 16.

54. Kasoju, N., et al., Transcriptomics of human multipotent mesenchymal stromal cells: Retrospective analysis and future prospects. Biotechnology Advances, 2017.

55. Vallabhaneni, K.C., et al., Extracellular vesicles from bone marrow mesenchymal stem/stromal cells transport tumor regulatory microRNA, proteins, and metabolites. Oncotarget, 2015. 6(7): p. 4953.

56. Kaur, H., et al., Next-generation sequencing: a powerful tool for the discovery of molecular markers in breast ductal carcinoma in situ. Expert review of molecular diagnostics, 2013. 13(2): p. 151-165.

57. Zhu, Y., et al., In-depth study on aminolysis of poly(c-caprolactone): Back to the fundamentals. Science China Chemistry, 2012. 55(11): p. 2419-2427.

58. Khurana, P., et al., HypoxiaDB: a database of hypoxia-regulated proteins. Database, 2013. 2013.

59. Niehage, C., et al., The cell surface proteome of human mesenchymal stromal cells. PloS one, 2011. 6(5): p. e20399.

60. Cho, K.-A., et al., RNA sequencing reveals a transcriptomic portrait of human mesenchymal stem cells from bone marrow, adipose tissue, and palatine tonsils. Scientific reports, 2017. 7(1): p. 17114.

61. Lv, F.-J., et al., Concise review: the surface markers and identity of human mesenchymal stem cells. Stem cells, 2014. 32(6): p. 1408-1419.

62. Kanehisa, M., The KEGG database. silico simulation of biological processes, 2002. 247: p. 91103.

63. Dennis, G., et al., DAVID: database for annotation, visualization, and integrated discovery. Genome biology, 2003. 4(9): p. R60.

64. Mathew, S.A., B. Chandravanshi, and R. Bhonde, Hypoxia primed placental mesenchymal stem cells for wound healing. Life Sciences, 2017.

65. Martin - Rendon, E., et al., Transcriptional profiling of human cord blood CD133+ and cultured bone marrow mesenchymal stem cells in response to hypoxia. Stem cells, 2007. 25(4): p. 1003-1012.

66. Zhang, J., et al., Identification of the haematopoietic stem cell niche and control of the niche size. Nature, 2003. 425(6960): p. 836-841. 
67. Gao, L., R. McBeath, and C.S. Chen, Stem cell shape regulates a chondrogenic versus myogenic fate through Rac1 and N - Cadherin. Stem cells, 2010. 28(3): p. 564-572.

68. Yim, E.K.F., et al., Proliferation and differentiation of human mesenchymal stem cell encapsulated in polyelectrolyte complexation fibrous scaffold. Biomaterials, 2006. 27(36): p. 6111-6122.

69. Zhuang, Y., et al., Chemokine stromal cell-derived factor 1/CXCL12 increases homing of mesenchymal stem cells to injured myocardium and neovascularization following myocardial infarction. Chinese medical journal, 2009. 122(2): p. 183-187.

70. Peled, A., et al., Dependence of human stem cell engraftment and repopulation of NOD/SCID mice on CXCR4. Science, 1999. 283(5403): p. 845-848.

71. Yamashita, T., et al., The microenvironment for erythropoiesis is regulated by HIF-2 $\alpha$ through VCAM-1 in endothelial cells. Blood, 2008. 112(4): p. 1482-1492.

72. Dahl, K.D.C., et al., Hypoxia-inducible Factor Regulates av83 Integrin Cell Surface Expression. Molecular Biology of the Cell, 2005. 16(4): p. 1901-1912.

73. Aomatsu, E., et al., Cell-cell adhesion through N-cadherin enhances VCAM-1 expression via PDGFRB in a ligand-independent manner in mesenchymal stem cells. International journal of molecular medicine, 2014. 33(3): p. 565-572.

74. Leonel, J.C.M.V., Engineering biomaterial surfaces with N-cadherin. 2014: University of Illinois at Urbana-Champaign.

75. Li, R., et al., Self-assembled $N$-cadherin mimetic peptide hydrogels promote the chondrogenesis of mesenchymal stem cells through inhibition of canonical Wnt/B-catenin signaling. Biomaterials, 2017. 145: p. 33-43.

76. Haÿ, E., et al., N - Cadherin/Wnt Interaction Controls Bone Marrow Mesenchymal Cell Fate and Bone Mass During Aging. Journal of cellular physiology, 2014. 229(11): p. 1765-1775.

77. Vega, S.L., et al., Single Cell Imaging to Probe Mesenchymal Stem Cell N-Cadherin Mediated Signaling within Hydrogels. Annals of biomedical engineering, 2016. 44(6): p. 1921-1930.

78. $\mathrm{Xu}$, L., et al., $\mathrm{N}$-cadherin regulates osteogenesis and migration of bone marrow-derived mesenchymal stem cells. Molecular biology reports, 2013. 40(3): p. 2533-2539.

79. Liu, F., et al., Changes in the expression of CD106, osteogenic genes, and transcription factors involved in the osteogenic differentiation of human bone marrow mesenchymal stem cells. Journal of bone and mineral metabolism, 2008. 26(4): p. 312-320.

80. Forristal, C.E., et al., Hypoxia inducible factors regulate pluripotency and proliferation in human embryonic stem cells cultured at reduced oxygen tensions. Reproduction, 2010. 139(1): p. 85-97.

81. Petruzzelli, R., et al., HIF-2 $\alpha$ regulates NANOG expression in human embryonic stem cells following hypoxia and reoxygenation through the interaction with an Oct-Sox cis regulatory element. PloS one, 2014. 9(10): p. e108309.

82. Du, W., et al., VCAM-1+ placenta chorionic villi-derived mesenchymal stem cells display potent pro-angiogenic activity. Stem cell research \& therapy, 2016. 7(1): p. 49.

83. Feng, W., et al., The angiogenic response is dictated by 83 integrin on bone marrow-derived cells. J Cell Biol, 2008. 183(6): p. 1145-1157.

84. Carmeliet, P., Integrin indecision. Nature medicine, 2002. 8(1): p. 14-16.

85. Kumar, C.C., et al., Targeting Integrins $\alpha$ v 83 and $\alpha$ v 85 for Bloking Tumor-Induced Angiogenesis, in Angiogenesis. 2000, Springer. p. 169-180.

86. Gutheil, J.C., et al., Targeted antiangiogenic therapy for cancer using Vitaxin: a humanized monoclonal antibody to the integrin $\alpha v$ B3. Clinical Cancer Research, 2000. 6(8): p. 30563061.

87. Di, Q., et al., Impaired cross-activation of 33 integrin and VEGFR-2 on endothelial progenitor cells with aging decreases angiogenesis in response to hypoxia. International journal of cardiology, 2013. 168(3): p. 2167-2176. 
88. Kračun, D., et al., The 83-Integrin Binding Protein B3-Endonexin Is a Novel Negative Regulator of Hypoxia-Inducible Factor-1. Antioxidants \& redox signaling, 2014. 20(13): p. 1964-1976.

89. Hayashi, H., et al., The Foxc2 transcription factor regulates angiogenesis via induction of integrin 83 expression. Journal of Biological Chemistry, 2008. 283(35): p. 23791-23800.

90. Robinson, S.D. and K.M. Hodivala-Dilke, The role of B3-integrins in tumor angiogenesis: context is everything. Current opinion in cell biology, 2011. 23(5): p. 630-637.

91. Martin, S.K., et al., Hypoxia-inducible factor-2 is a novel regulator of aberrant CXCL12 expression in multiple myeloma plasma cells. Haematologica, 2010. 95(5): p. 776-784.

92. Skuli, N., et al., Endothelial deletion of hypoxia-inducible factor-2 $\alpha$ (HIF-2 $\alpha$ ) alters vascular function and tumor angiogenesis. Blood, 2009. 114(2): p. 469-477.

93. Wouters, J., et al., A novel hypoxia-associated subset of FN1highMITFlow melanoma cells: identification, characterization, and prognostic value. Modern Pathology, 2014. 27(8): p. 1088-1100.

94. Hughes, M.D., et al., HIF-2 $\alpha$ downregulation in the absence of functional VHL is not sufficient for renal cell differentiation. Cancer cell international, 2007. 7(1): p. 13.

95. Ivanovic, Z. and V.-L. M., Anaerobiosis and StemnessL An Evolutionary Paradigm for Therpeutic Applications. 2015: Cambridge Academic Press.

96. Busletta, C., et al., Dissection of the Biphasic Nature of Hypoxia - Induced Motogenic Action in Bone Marrow - Derived Human Mesenchymal Stem Cells. Stem cells, 2011. 29(6): p. 952963.

97. Semenza, G.L., Regulation of Mammalian O2 Homeostasis by Hypoxia-Inducible Factor 1. Annual Review of Cell and Developmental Biology, 1999. 15(1): p. 551-578.

98. Semenza, G.L., Dynamic regulation of stem cell specification and maintenance by hypoxiainducible factors. Molecular aspects of medicine, 2016. 47: p. 15-23.

99. Majmundar, A.J., W.J. Wong, and M.C. Simon, Hypoxia-inducible factors and the response to hypoxic stress. Molecular cell, 2010. 40(2): p. 294-309.

100. Bracken, C.P., et al., Cell-specific regulation of hypoxia-inducible factor (HIF)-1 $\alpha$ and HIF-2 $\alpha$ stabilization and transactivation in a graded oxygen environment. Journal of Biological Chemistry, 2006. 281(32): p. 22575-22585.

101. Grayson, W.L., et al., Hypoxia enhances proliferation and tissue formation of human mesenchymal stem cells. Biochemical and biophysical research communications, 2007. 358(3): p. 948-953.

102. Keith, B., R.S. Johnson, and M.C. Simon, HIF1 $\alpha$ and HIF2 $\alpha$ : sibling rivalry in hypoxic tumour growth and progression. Nature Reviews Cancer, 2012. 12(1): p. 9-22.

103. Kondo, K., et al., Inhibition of HIF2 $\alpha$ is sufficient to suppress pVHL-defective tumor growth. PLoS Biol, 2003. 1(3): p. e83.

104. Covello, K.L., et al., HIF-2 $\alpha$ regulates Oct-4: effects of hypoxia on stem cell function, embryonic development, and tumor growth. Genes \& development, 2006. 20(5): p. 557-570.

105. Gordan, J.D., et al., HIF-2 $\alpha$ promotes hypoxic cell proliferation by enhancing c-myc transcriptional activity. Cancer cell, 2007. 11(4): p. 335-347.

106. Wiesener, M.S., et al., Widespread hypoxia-inducible expression of HIF-2 $\alpha$ in distinct cell populations of different organs. The FASEB Journal, 2003. 17(2): p. 271-273.

107. Shang, J., et al., Roles of Hypoxia During the Chondrogenic Differentiation of Mesenchymal Stem Cells. Current Stem Cell Research \& Therapy, 2014. 9(2): p. 141-147.

108. Zhu, C., et al., Hypoxia-inducible factor-2 alpha promotes the proliferation of human placenta-derived mesenchymal stem cells through the MAPK/ERK signaling pathway. Scientific reports, 2016. 6(35489).

109. Corbion. PURASORB ${ }^{\circledR}$ PL 24 Product data sheet. 2015 March 2015 [cited 2016 Feb]; Available from: https://www.corbion.com/static/downloads/datasheets/46d/PURASORB\%20PL\%2024.pdf. 
110. Hung, S.-C., et al., Short-term exposure of multipotent stromal cells to low oxygen increases their expression of CX3CR1 and CXCR4 and their engraftment in vivo. PloS one, 2007. 2(5): $p$. e416.

111. Abagnale, G., et al., Surface topography guides morphology and spatial patterning of induced pluripotent stem cell colonies. Stem cell reports, 2017. 9(2): p. 654-666.

112. Abagnale, G., et al., Surface topography enhances differentiation of mesenchymal stem cells towards osteogenic and adipogenic lineages. Biomaterials, 2015. 61: p. 316-326.

113. Jin, C., et al., Nanoscale surface topography enhances cell adhesion and gene expression of madine darby canine kidney cells. Journal of Materials Science: Materials in Medicine, 2008. 19(5): p. 2215-2222.

114. Fiedler, J., et al., The effect of substrate surface nanotopography on the behavior of multipotnent mesenchymal stromal cells and osteoblasts. Biomaterials, 2013. 34(35): p. 8851-8859.

115. Song, S., et al., The synergistic effect of micro-topography and biochemical culture environment to promote angiogenesis and osteogenic differentiation of human mesenchymal stem cells. Acta biomaterialia, 2015. 18: p. 100-111. 